جامعـة نيويورك أبـوظـبي $\stackrel{\uplus}{i}$ NYU $\mid$ ABU DHABI

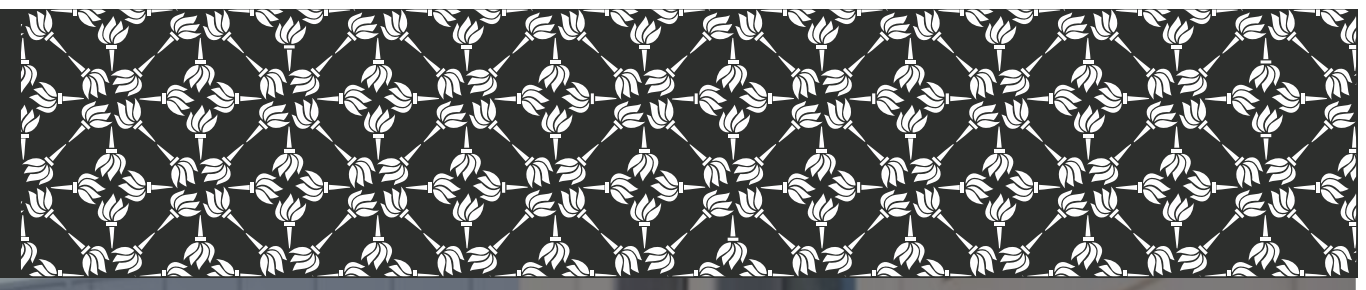

\title{
An Experiment on Gender Representation in Majoritarian Bargaining
}

\author{
Andrzej Baranski, Diogo Geraldes, Ada \\ Kovaliukaite and James Tremewan
}

Working Paper \# 0060

January 2021 


\title{
An Experiment on Gender Representation in Majoritarian Bargaining*
}

\author{
Andrzej Baranski ${ }^{\dagger} \quad$ Diogo Geraldes ${ }^{\ddagger} \quad$ Ada Kovaliukaite ${ }^{\S}$ \\ James Tremewan !
}

January 3, 2021

\begin{abstract}
Does the gender composition of committees affect negotiations in majoritarian bargaining? We report the results of an experiment in which subjects are placed in triads to negotiate the division of a sum of money under majority rule and the gender composition of the group is manipulated, ranging from all female (FFF), female majority (FFM), male majority (MMF), to all male (MMM). Results show that men are more likely to make the opening offer, and contrary to our hypothesis, agreements are reached fastest in MMM and slowest in FFF. The proportion of grand coalitions is increasing in the number of females while minimal winning coalitions (MWCs) increase monotonically in the number of males. MWCs are disproportionately more likely to be same-gender in MMF, which leads to a gender gap in earnings compared to FFM. When provisional MWCs form prior to a final agreement, excluded men are more proactive than excluded women in attempting to break the coalition by making alluring offers, which partially explains why mixed gender MWCs are less frequent in MMF compared to FFM. Notably, some females adopt male-type behavior in MMF regarding their initial proposals and aggressiveness when left out from a MWC.
\end{abstract}

${ }^{*}$ We would like to thank participants at internal seminars at Maastricht University, NYUAD, University of Amsterdam, University of Waikato, Utrecht University, and at the International ESA 2019, iSEE 2019 at NYUAD conferences. We are particularly indebted for the comments of Katherine Baldiga, Christine Exley, Becky Morton, Ernesto Reuben, Arno Riedl, Aldo Rustichini, and Lise Vesterlund.

${ }^{\dagger}$ Division of Social Science, NYU Abu Dhabi. Email: a.baranski@nyu.edu.

†Utrecht School of Economics, Utrecht University, the Netherlands. Email: diogogeraldes@gmail.com.

${ }^{\S}$ Division of Social Science, NYU Abu Dhabi. Email: ada.kovaliukaite@nyu.edu.

IIDepartment of Economics, University of Auckland, New Zealand. Email: james.tremewan@auckland.ac.nz 


\section{Introduction}

Boards of directors in business corporations, boards of trustees, self-managed teams, legislatures, and panels of judges are a few examples of the many settings where members typically engage in bargaining to reach agreements. Evidence from multiple studies and surveys reveal that women are largely underrepresented in decision-making bodies all over the world across business, economic, and political domains. ${ }^{1}$ This imbalance has led to wider calls for policies aiming to close the gender gap in female representation in decision-making bodies (e.g., European Commission Gender Equality Strategy 2020-2025 and United Nations 2030 Sustainable Development Goals).

Besides a first-order equity concern for gender parity per se, it is often argued that women's under-representation in committees may systematically lead to less desirable outcomes. ${ }^{2}$ Such considerations may become more important if decisions are reached via majority voting since gender majority members might coalesce and discriminate against members of the minority, further diminishing women's actual effect on decision-making. ${ }^{3}$ However, the precise way in which the gender composition of committees causally affects multilateral bargaining outcomes is not known and warrants a careful investigation. Are agreements more inclusive as the number of women increases? Are women faster at reaching agreements than men? Will majority members discriminate against minority members, and if so, which gender is more prone to doing so? Are men more likely than women to make an opening offer or does this depend on the gender of the bargaining partners?

To answer these questions, we conduct a laboratory experiment in which subjects are randomly assigned to one of the following treatment conditions: all female (FFF), female majority (FFM), male majority (MMF), or all male (MMM). In the experiment, participants are placed in groups of three in order to divide a sum of money through a free-form bar-

\footnotetext{
${ }^{1}$ Only $23 \%$ of members of Congress and $26 \%$ of Senators are women in $116^{\text {th }}$ United States Congress (2019-2021). In 2019, 24.9\% of all members of parliamentary bodies around the world were women (Interparliamentary Union, 2020). Women represent only $22 \%$ of chief executives in the United States (Huang et al., 2019).

${ }^{2}$ For example, Bourreau-Dubois et al. (2020) find that French judge panels impose higher child support payments when the judges are all women (regardless of the gender of the creditor) compared to mixed panels, but there is no difference with all male panels. Boyd et al. (2010) find that males in judge panels lacking women are less likely to rule in favor of plaintiffs in cases of discrimination in the United States. All-female groups in a management game are more likely to invest in social corporate responsibility, however they perform lower compared to mixed and all male groups (Apesteguia et al., 2012). Female students randomly assigned to malemajority study groups in an Economics course are more likely to drop the course than women in other groups (Shan, 2020). We discuss this literature further in our concluding remarks.

${ }^{3}$ Note that such behavior could be vetoed by the minority members under a unanimity rule.
} 
gaining protocol. Agreements are reached via majority voting, and importantly, delays are monetarily costly in terms of a shrinking amount of money available to divide. To reach a final agreement, subjects first enter a pre-agreement which will become ratified only if at least two group members support it for a fixed period of time. During the ratification period, a member that is not part to the pre-agreement may engage in making offers in order to lure partners into a new coalition and impede the ratification, and parties to the preliminary agreement are free to reconsider and propose alternatives too. To the best of our knowledge, we are the first to experimentally assess the impact of the gender composition of committees on multilateral bargaining agreements.

Previous laboratory studies that endogenously vary gender matching in bargaining have exclusively focused on bilateral bargaining settings such as the dictator and ultimatum games (see Eckel and Grossman (2001); Solnick (2001); Sutter et al. (2009); Eriksson and Sandberg (2012); Dittrich et al. (2014); Hernandez-Arenaz and Iriberri (2020); Exley et al. (2020)). ${ }^{4}$ Taken together, the results from the previous studies indicate that women are more generous than men (Engel, 2011; Bilén et al., 2020; Eckel et al., 2008). While these simple bilateral settings are a natural starting point to investigate behavior and valuable insights have been gained by focusing on them, we believe they do not capture essential elements inherent to the bargaining process of the examples we have set forth in our opening paragraph. In particular, coalition formation and dissolution is central to the back and forth negotiations typically described in legislative bodies in which temporary informal agreements can be dissolved later and new coalitions may form. Moreover, in many contexts it is rarely pre-established who makes the first proposal which is fixed in experiments using a structured bargaining protocol such as the dictator, ultimatum, or power to take games. And critical to the aim of the present paper, bilateral bargaining protocols do not allow studying the impact of changing the representation of women from minority to majority status.

Our experimental setting presents three novel features that differentiate it from previous studies of gender in bargaining games. First, by implementing a multilateral setting, we naturally allow for agreements to include both minimum winning coalitions (MWCs) and grand coalitions (GCs) in which all members receive a positive share. Second, our setting endogenizes the first-mover. That is, since any member of a bargaining triad can make an offer at any point in time, we can assess whether a gender difference in making an opening offer exists. Third, to capture the behavior of members excluded from a coalition, our pro-

\footnotetext{
${ }^{4}$ Gender differences in bargaining have also been studied in the field. See Castillo et al. (2013); Leibbrandt and List (2015), Andersen et al. (2018), Hernandez-Arenaz and Iriberri (2018), and Säve-Söderbergh (2019).
} 
tocol requires a ratification period before a temporary agreement becomes binding in which we can observe behavior of excluded members.

We find that the overall distribution of shares becomes more inclusive as the number of females increases, with GCs averaging 26 percent of agreements in FFF and 13 percent in MMM. Also, consistent with previous findings in structured multilateral bargaining, MWCs are modal in all treatments of the experiment.

Do majorities discriminate against minorities? We find that $67 \%$ of MWCs are mixed gender in FFM while only 58\% in MMF. Note that perfect randomization in partner choice means that the coalition will be mixed $2 / 3$ of the time, which coincides with what we observe for FFM. While this may suggest that men discriminate against women in MMF, an exploratory investigation of the bargaining process reveals this is not the case. In fact, when males make the first offer, they invite the only female in the group more often (56\% of the time). However, left-out males are quite aggressive and insistent in their attempts to break the gender-mixed MWC, with included males more likely to break out of the interim agreement. These two findings are not in line with males directly or intentionally discriminating against females.

Regarding the bargaining process, we hypothesized that men would be more prone to making opening offers, which we find in the data. We also hypothesized that all-women groups would reach agreements faster than all-male groups, but the data does not support this hypothesis as agreements are reached significantly faster in MMM compared to FFF, and thus, efficiency is lowest in FFF.

The article proceeds as follows. In section 2 , we present the design of our experiment. Next, in section 3, we formulate our research hypotheses based on a review of the existent literature. In section 4, we present our results. Section 5, discusses and concludes the article.

\section{Experimental Design}

\subsection{The bargaining game}

Subjects were randomly grouped in triads to divide 12 tokens which corresponded to 36 euros. A silhouette indicating the gender of each member of the committee was displayed. At any moment during the bargaining process, any subject in a given triad could: i. Make a proposal on how to divide the twelve points; ii. Provisionally support (or not) an existing proposal; or iii. Withdraw the proposal after having made one. Agreements were reached 
when at least two members of the triad agreed on a split for a ten-second ratification period. This design closely follows the unstructured bargaining protocol of Tremewan and Vanberg (2016, 2020).

Importantly, each second that goes by during the game, the remaining fund decreases by $1 \% .^{5}$ In case 150 seconds went by without agreement, all players earned 0 . Subjects experienced the described bargaining protocol over twelve periods. The experiment was computerized using z-Tree software (Fischbacher, 2007). Screenshots, experimental instructions, and details of the bargaining interface can be found in the Online Appendix.

\subsection{Treatments and Session Details}

We conducted four treatments (between-subjects): All-female (FFF), Female-majority (FFM), Male-majority (MMF), and All-male (MMM). This means that the gender composition of the triads was fixed in each treatment even though the triads were randomly re-matched in each of the 12 periods. Gender was never mentioned in the instructions or invitation email.

Following the same protocol of Geraldes (2020), we recruited equal number of subjects of each gender to participate in each session, so that upon arriving to the laboratory subjects would see a gender balanced group. During each session, we conducted two treatments concurrently but subjects only participated in one of them. Six sessions were for the treatments FFF and MMM, and the other six sessions were for FFM and MMF. ${ }^{6}$

Prior to the start of the session, a demographic survey was conducted which asked for gender among several other questions. In our sample, it was always the case that the reported gender matched what the experimenters determined when assigning subjects to computer terminals.

A total of 282 Subjects participated in our experiment. They were undergraduate students from Maastricht University, mostly from the School of Business and Economics. Only one period was randomly selected for payment so as to induce the one-shot game incentives (Azrieli et al., 2018). A show-up fee of 5 euros was offered and earnings averaged 16.5 euros. Sessions lasted about 60 minutes.

\footnotetext{
${ }^{5}$ The monetary value of points would continue to fall each second during the ratification period.

${ }^{6}$ For the mixed gender sessions, $1 / 3$ of the men were paired with $2 / 3$ of the women for FFM and the complement group assigned to treatment MMF. This particular recruiting and treatment allocation procedure was done in order to avoid as much as possible revealing the objective of the experiment. If, instead, we run sessions with only the single gender treatments, the experiment's purpose could be inferred.
} 


\section{Hypotheses and Previous Literature}

There is a large and growing experimental literature studying majoritarian bargaining games. One of the most widely studied models in the laboratory is the legislative bargaining game by Baron and Ferejohn (1989). In this game, players are randomly selected to propose a distribution of a unit of wealth, followed by a voting stage in which a majority must approve. In case of rejection, the process repeats itself and discounting occurs. ${ }^{7}$

Another approach to the study of multilateral majoritarian bargaining in the laboratory, which we pursue in the present paper, is to allow for free-form protocols in which time is continuous and any player may propose a division of the pie at any point (and withdraw it). ${ }^{8}$ Two recent studies (Tremewan and Vanberg, 2016, 2020) have shown that bargaining outcomes (i.e., agreed splits) are quite similar in structured and unstructured bargaining protocols despite the differences in procedures.

Without pretending to suggest that one approach is better than the other, we consider that the unstructured protocol fits our investigation purposes better because it allows for an implementation of a bargaining process more in line with motivating examples we have set forth. Even when formal rules are in place in settings like legislatures or bankruptcy negotiations, informal back-and-forth bargaining is still present. Thus, an unstructured bargaining game certainly captures better the realm of such type of real world settings. Importantly, the fundamental purpose of this study is to assess men's and women's bargaining behavior; not to test game theoretical predictions. Finally, the present work also opens the question of whether our findings translate to structured bargaining protocols, which we believe presents an interesting venue for further exploration.

We summarize the evidence from Baron and Ferejohn experiments and those of Tremewan and Vanberg in Table 1. While it is clear that MWCs are modal representing around 60 percent of all accepted proposals in Baron and Ferejohn (1989) experiments (periods 610 ), the proportion of grand coalitions (GCs) is far from negligible. A similar pattern arises in free-form experiments. Also, a noticeable pattern is that MWCs become more popular as subjects gain experience in bargaining. Thus, we pose the first hypothesis of our experiment:

\footnotetext{
${ }^{7}$ For experiments with cheap talk see Agranov and Tergiman (2014); Baranski and Kagel (2015); Agranov et al. (2020). For veto treatments see Kagel et al. (2010). For one-round games with exogenous continuation values see Diermeier and Gailmard (2006). For treatments with varying voting weights see Diermeier and Morton (2005); Fréchette et al. (2005).

${ }^{8}$ The unstructured bargaining approach has a long history in bilateral bargaining, see Roth (1987); Roth et al. (1981); Roth and Murnighan (1982).
} 
Table 1: Coalition Size in 3-Players Majoritarian Bargaining Experiments ${ }^{1}$

\begin{tabular}{|c|c|c|c|c|}
\hline & \multicolumn{4}{|c|}{ Coalition Size } \\
\hline & \multicolumn{2}{|c|}{ Minimum Winning } & \multicolumn{2}{|c|}{ Grand } \\
\hline & Periods 1-5 & Periods $6-10$ & Periods 1-5 & Periods 6-10 \\
\hline \multicolumn{5}{|l|}{ Baron and Ferejohn Protocol } \\
\hline Diermeier and Morton (2005) & 0.60 & 0.60 & 0.40 & 0.40 \\
\hline Fréchette et al. (2005) & 0.58 & 0.66 & 0.42 & 0.34 \\
\hline Kagel et al. (2010) & 0.44 & 0.60 & 0.55 & 0.40 \\
\hline Baranski and Kagel (2015) & 0.70 & 0.71 & 0.30 & 0.29 \\
\hline Bradfield and Kagel (2015) & 0.45 & 0.52 & 0.55 & 0.47 \\
\hline Laroze et al. $(2020)^{2}$ & \multicolumn{2}{|c|}{0.52} & \multicolumn{2}{|c|}{0.48} \\
\hline \multicolumn{5}{|l|}{ Free-form Bargaining } \\
\hline Murnighan and Roth $(1980)^{2,3}$ & \multicolumn{2}{|c|}{0.94} & \multicolumn{2}{|c|}{0.06} \\
\hline Tremewan and Vanberg $(2016)^{4}$ & 0.37 & 0.62 & 0.52 & 0.46 \\
\hline Tremewan and Vanberg (2020) & 0.56 & 0.85 & 0.44 & 0.15 \\
\hline \multicolumn{5}{|c|}{$\begin{array}{l}{ }^{1} \text { Data is from treatments in which verbal communication is not allowed, information on gender or other } \\
\text { demographics is not provided, decision makers act individually (not in teams), and subjects are randomly } \\
\text { rematched after each period. Discounting varies by study. Accepted proposals only. Data obtained from } \\
\text { Baranski and Morton (2020). } \\
{ }^{2} \text { We did not have the raw data hence we pool all periods of play as reported in the paper. } \\
{ }^{3} \text { Experiments had only male participants and were not computerized. } \\
{ }^{4} \text { In this experiment, payoffs accrue to subjects in a given period for every second they are in agreement. We } \\
\text { report the percentage of time for which each allocation was in place. }\end{array}$} \\
\hline
\end{tabular}


Hypothesis 1. MWCs are the modal allocation of the surplus. The prevalence of MWCs increases with experience regardless of the gender composition of the bargaining group.

Hypothesis 1 is silent on three important aspects. First, is there a gender difference in the likelihood to propose a MWC or a GC? Second, conditional on a MWC being proposed, is there a preference in the gender of the invited partner? Third, conditional on a MWC being proposed, how will the pie be split within the coalition?

With the exception of Laroze et al. (2020), we are unaware of any other multilateral bargaining experiment in which the gender of group members is displayed intentionally and/or gender composition of the committee is varied exogenously. There are several important differences between the studies. First, our study is exclusively focused on assessing the effect of displaying gender information on the bargaining process whereas in Laroze et al. information about gender, race, and political orientation is publicly displayed simultaneously. Second, we exogenously set the gender composition of the group and keep it fixed within a session (which is essential to have subjects exposed to only one treatment) while in Laroze et al. group gender composition is randomly formed and varies within periods of play and sessions. Third, we study an unstructured bargaining process whereas in Laroze et al. subjects play a Baron and Ferejohn protocol which preestablishes the order of moves. The authors find no effect of race or gender on proposer power or coalition partner choice, but report that sharing of the pie decreases as ideological distance increases. We should note, though, that in their setting subjects simultaneously observe the gender, race, and political ideology of other bargainers. Thus, as the authors acknowledge, the lack of a gender effect could be due to the higher importance of social desirability in their setting.

Hitherto, we lack data on the effect of gender on multilateral bargaining games. Thus, we will draw on insights from meta-analyses of the experimental literature on simple bilateral bargaining settings, namely, the dictator game to elaborate our hypothesis on gender differences. Moreover, as we are not aware of a meta analysis of gender differences in ultimatum games, we base our hypothesis regarding gender differences also on the studies by Eckel and Grossman (2001), Solnick (2001), and McGee and Constantinides (2013) and the survey evidence in Eckel et al. (2008).

The results for dictator games meta-analyses are summarized in Table 2 and for ultimatum games with gender pairing in Table 13 of the Appendix. Collectively, these studies indicate that women share more than men, and importantly, Rand et al. (2016) show that the altruistic effect of time pressure is stronger on women. The latter result is particularly pertinent for our setting since the fear of exclusion from a coalition may create an urgency 
to reach an agreement. While this urgency is faced by both men and women, according to Rand et al. (2016) this effect moves women closer to equal sharing than men, because they will act intuitively.

Importantly, evidence from dictator games with 2 recipients in Fehr et al. (2006) shows that women are 10 percent more likely than men to choose the most egalitarian outcome among a set of fixed alternatives.

Table 2: Meta-analyses Results on Gender Differences in Dictator Games

\begin{tabular}{|c|c|c|c|}
\hline Study & Finding Summary & Significance & Sample \\
\hline Engel (2011) & $\begin{array}{l}\text { Women transfer } 5.8 \text { more percentage } \\
\text { points of the total pie than men. }\end{array}$ & $\mathrm{p}<0.1$ & 12 studies \\
\hline Bilén et al. (2020) & $\begin{array}{l}\text { Women transfer } 4.2 \text { percentage points } \\
\text { more of the total pie than men. }\end{array}$ & $\mathrm{p}<0.001$ & $\begin{array}{l}53 \text { studies } \\
(15,042 \\
\text { obs. })^{1}\end{array}$ \\
\hline Rand et al. (2016) & $\begin{array}{l}\text { The effect of increasing reliance on in- } \\
\text { tuition by experimentally reducing re- } \\
\text { sponse time on transfers is } 5.5 \text { percent- } \\
\text { age points larger in women than men. }\end{array}$ & $\mathrm{p}<0.001$ & $\begin{array}{l}22 \text { studies } \\
(4,366 \\
\text { obs. })\end{array}$ \\
\hline
\end{tabular}

${ }^{1}$ This study uses raw data, while the others user effect sizes.

Hypothesis 2. The proportion of GC agreements is increasing in the number of women in the bargaining group.

We now proceed to hypothesize with respect to the gender composition of the coalitions. A natural conjecture is that, if subjects in an anonymous bargaining game randomize over whom they invite to their coalition, gender information can alter the probability with which men and women will invite each other. What is not clear is which direction to expect: will there be same-gender favoritism in coalition formation? Or will members of the gender majority in the group seek coalitions with the minority player? Again, given the paucity of previous studies assessing the effect of gender composition of the group on coalition formation $^{9}$, we draw on insights from related games.

The meta-analysis on discrimination in experiments by Lane (2016) shows evidence of a significant outgroup bias for gender identity: both men and women discriminate positively

\footnotetext{
${ }^{9}$ Unfortunately Laroze et al. (2020) do not report the probability of inclusion into MWCs by proposer and voter gender.
} 
towards the opposite gender. According to their estimates, the probability of discriminating in favor of the opposite gender is almost 33 percent with an effect size of close to 50 percent. The results in Eckel and Grossman (2001) for male responders' acceptance behavior in ultimatum bargaining games are in line with this pattern: men are more likely to accept an offer (controlling for the share) when offered by a female, than a male. However, females are more likely to accept offers from other females. The latter result is not supported in the study by Solnick (2001), where female pairs account for the largest rejection rates of all pairings. Considering this mixed evidence, we hypothesize no gender differences to arise in the mixed coalitions emerging in treatments FFM and MMF.

Hypothesis 3. Conditional on a MWC being agreed upon, mixed coalitions are equally likely to be formed in heterogeneous groups (i.e., FFM and MMF) regardless of which gender is the majority.

Conditional on a mixed coalition, how will payoffs be divided? Considering the previous results that women are more generous than men, and the findings by Eckel and Grossman (2001); Solnick (2001) that women are offered typically smaller shares of the pie than men, we believe that women will obtain smaller shares in mixed coalitions. However, note that a women being offered a small share by a man in a mixed coalition in treatment FFM has the option to partner with another women in order to raise her share. Thus, we believe that payoff asymmetry in favor of males will be more prominent in mixed coalitions when men are the majority (MMF).

Hypothesis 4. Women receive a smaller share than men in mixed coalitions when men are the group majority, but not when women are the majority.

We now discuss our hypothesis on efficiency, which in our setting can be measured by the time needed to reach an agreement. Recall that payoffs fall by $1 \%$ each second, thus groups that are quicker to agree will enjoy higher aggregate payoffs. In light of the finding that women are more generous, we should expect faster agreements in FFF compared to MMM. However, offers are only part of the story since the proposals can be rejected. The evidence on rejections from ultimatum games is mixed. Eckel and Grossman (2001) finds that, when paired with the same gender, females are less likely to reject an offer than males (3.1\% vs $18.8 \%$ ). The latter result is in line with McGee and Constantinides (2013) who find a smaller differences (14.7 vs 18.2). However, Solnick (2001) finds the opposite pattern ( $23.1 \%$ vs $4.5 \%)$. Overall, the evidence seems to suggest that women are more agreeable and 
generous then men (Eckel et al., 2008). ${ }^{10}$ We therefore hypothesize that:

Hypothesis 5. Groups with only women reach agreements faster than groups with only men.

Thus far, we have hypothesized about bargaining outcomes but not about the bargaining process per se. Since we implement a free-form protocol of negotiations, our analysis in this matter will be essentially exploratory. Nonetheless, we hypothesize about one specific variable of interest: the opening offer. Will men and women differ in their willingness to move first? Note that in structured bargaining protocols, such as the Baron and Ferejohn, ultimatum, and dictator games the proposer role is exogenously assigned. Thus, to our knowledge, we are the first to experimentally assess the propensity to move first since in a multilateral bargaining setting.

Exley et al. (2020) study a wage setting game between an employer and an employee that have worked (i.e., real effort task) to generate a contribution that determines joint profits to be divided via bargaining. In their main treatment, employees may choose to enter a wage negotiation game and their results show that women are significantly less likely than men to enter negotiations (66\% versus $74 \%$ ).

Evidence from other domains is also illuminating on this matter. For example, Coffman (2014) finds that, controlling for ability, women are less likely than men to contribute their ideas (e.g., answer to a quiz). Vast experimental evidence following Niederle and Vesterlund (2007) shows that men are more likely to sort into competitive environments than women. In a group decision domain, Ertac and Gurdal (2012) show that women and men differ substantially in the willingness to make decision on behalf of their group: $55 \%$ of women compared to $86 \%$ of men volunteer to make a group decision. Men are also more likely than women to give advice on how to play a game strategically (Cooper and Kagel, 2016).

If we assume that the forces driving the willingness to enter into a negotiation, the contribution of an idea, offering advice on strategic play, or sorting into competition to affect bargaining postures, then we should expect women to take a more passive stance in our game. Moreover, the competitive nature of the bargaining setting may foster even larger differences in willingness to propose if the environment is perceived as male-typed. Our last hypothesis is therefore:

Hypothesis 6. In gender mixed groups, men are more likely than women to make the opening proposal.

\footnotetext{
${ }^{10}$ Hernandez-Arenaz and Iriberri (2020) report that men take longer to reach agreements in an alternating offer bargaining game when there are asymmetries between players, but not in a perfectly symmetric case where the equal split prevails.
} 


\section{Results}

In Table 3, we summarize the structure of the data. In total, we observed 288 bargaining games in the FFM and MMM treatments, respectively, and 276 bargaining games in the FFM and FMM treatments, respectively. The reported descriptive statistics and figures consider the bargaining games at the (average) matching group level per period as a single observation ( $n=72$ per treatment). The significance tests consider the bargaining games at the (average) matching group level across periods as a single observation $(\mathrm{n}=6$ per treatment).

Table 3: Description of Data Set

\begin{tabular}{cccccc}
\hline Treatment & Subjects & Periods & Agreements ${ }^{1}$ & $\begin{array}{c}\text { Matching } \\
\text { groups }\end{array}$ & $\begin{array}{c}\text { Subjects per } \\
\text { matching group }\end{array}$ \\
\hline FFF & 72 & 12 & 288 & 6 & 12 \\
FFM & 69 & 12 & 276 & 6 & $9,12^{2}$ \\
MMF & 69 & 12 & 276 & 6 & $9,12^{2}$ \\
MMM & 72 & 12 & 288 & 6 & 12 \\
\hline
\end{tabular}

${ }^{1}$ An agreement refers to a bargaining outcome (there are no disagreements in our sample). It is the number of periods times the number of subjects divided by 3 .

${ }^{2}$ In one of our sessions, not enough subjects showed up, hence there is one matching group with 9 subjects.

In subsection 4.1 , we test our hypotheses regarding bargaining outcomes. To this end, we follow the same order of our stated hypotheses. In subsection 4.2, we conduct an exploratory analysis on individual bargaining strategies.

\subsection{Bargaining Outcomes}

First, we note that there are no disagreements in our sample, thus we have a monetary division for every game played.

\subsubsection{Final agreements: Type of coalitions}

We start by analyzing the type of distributions that triads agreed upon, independently of the bargaining processes duration. In Table 4, we report the proportion of MWCs and GCs for each treatment. Clearly, the MWCs are modal representing approximately 80 percent of all 
agreements. Moreover, in Figure 1, we clearly see that the proportion of GCs is decreasing (and thus MWCs is increasing) with experience in all treatments. ${ }^{11}$

Table 4: Proportion of Minimum and Grand Coalitions By Treatment

\begin{tabular}{lcccc}
\hline & FFF & FFM & FMM & MMM \\
\hline Minimum Winning Coalitions & & & & \\
$\quad$ All & 0.740 & 0.739 & 0.844 & 0.872 \\
$\quad$ Equal Splits & 0.535 & 0.551 & 0.594 & 0.635 \\
Grand Coalitions & & & & \\
$\quad$ All & 0.260 & 0.257 & 0.152 & 0.128 \\
$\quad$ Equal Splits & 0.149 & 0.178 & 0.109 & 0.090 \\
Gender Composition of MWCs & & & & \\
$\quad$ mixed-gender & n.a. & 0.67 & 0.58 & n.a. \\
same-gender & n.a. & 0.33 & 0.42 & n.a. \\
\hline
\end{tabular}

Does the effect of experience vary by treatment? A linear probability model was conducted regressing a dichotomous variable for whether or not an agreement is a GC on treatment dummies, a period trend, and its interaction with each treatment. We did not find any significant difference in the rate of GC decay by treatment.

In short, Hypothesis 1 is supported.

Result 1. In line with Hypothesis 1, we find that: $i$. 79.9 percent of all agreements are MWCs and 19.9 are $G C s^{12}$; ii. The prevalence of MWCs increases with experience, regardless of the gender composition of the bargaining group.

Moreover, Table 4 shows a clear pattern: as the number of females increases in the group so does the proportion of GCs. To probe the statistical significance of these observations, we conduct a probit regression (clustering at the matching group level) of the probability of GC on the number of females, the marginal effects are reported in Table 5. We also accounted for a period trend (and its interaction with the number of females) in a second model (column 4).

\footnotetext{
${ }^{11} \mathrm{~A}$ linear probability model corroborates this result. In an unreported regression, we regressed a dichotomous variable for whether or not an agreement is a GC on treatment dummies, a period trend, and its interaction with each treatment, and we did not find any significant difference in the rate of GC decay by treatment.

${ }^{12}$ There are 2 instances in which one member obtains the entire surplus. We omit these two instances throughout our analysis since they represent only $0.18 \%$ of all bargaining games.
} 
Table 5: Marginal Effects of Probit models for Grand Coalition Agreement

\begin{tabular}{lcccc}
\hline & All Periods & Periods 1-6 & Period 7-12 & All Periods \\
\hline Number of Females & $0.050^{* * *}$ & $0.060^{* *}$ & $0.040^{*}$ & $0.050^{* * * *}$ \\
& $(0.019)$ & $(0.027)$ & $(0.021)$ & $(0.019)$ \\
& & & & $-0.029^{* * *}$ \\
Period & & & & $(0.005)$ \\
\hline$N$ & 1128 & 564 & 564 & 1128 \\
\hline
\end{tabular}

Standard errors clustered at the group level.

See Appendix Table 14 for coefficients.

$* p<0.1, * * p<0.05, * * * p<0.01$

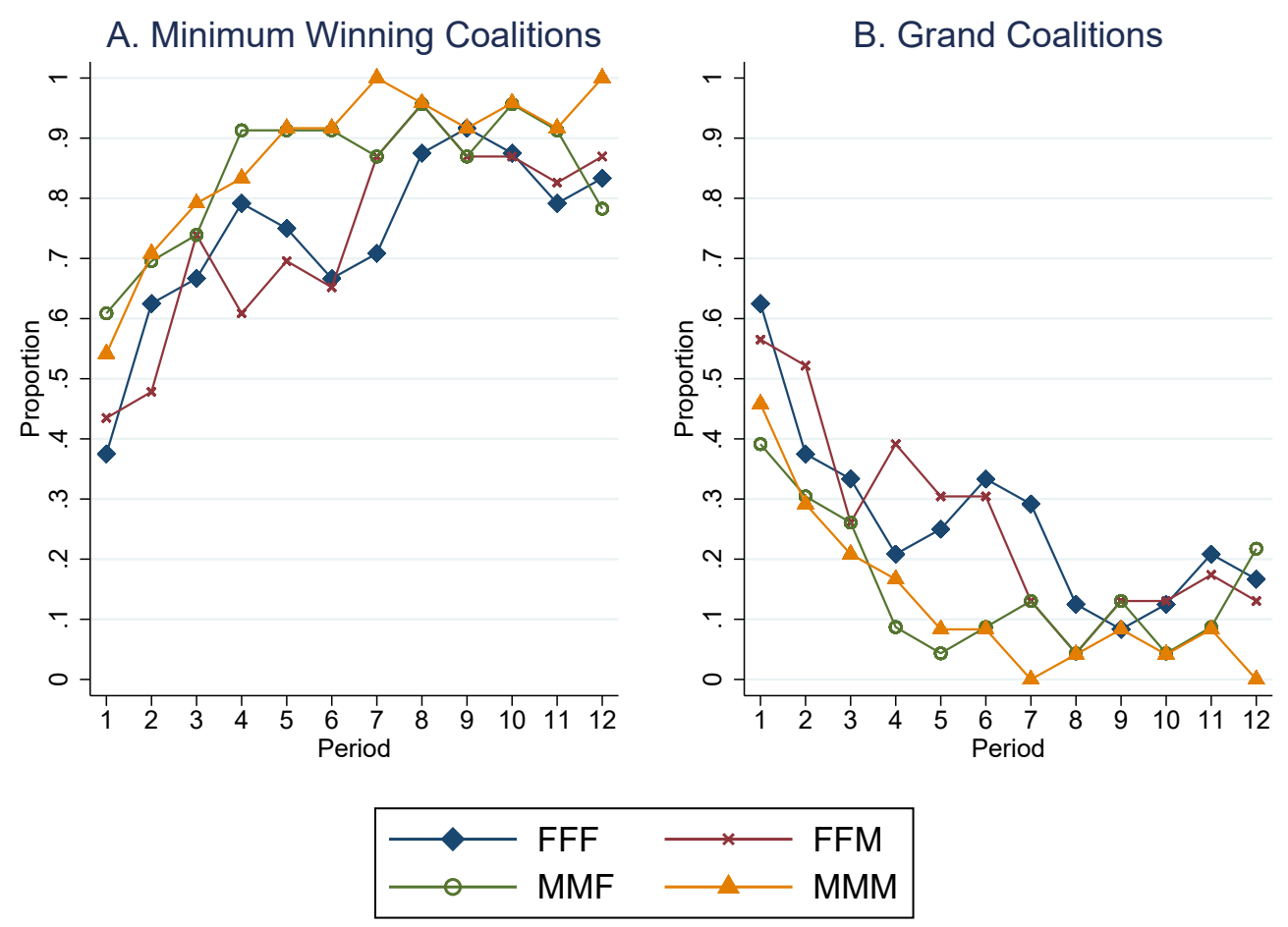

Figure 1: Minimum Winning and Grand Coalitions over Periods of Play, By Treatment 
Our regression show that each additional female in a group represents an increase in 5 percentage points in the probability of observing a GC, in support of Hypothesis $2 .{ }^{13}$

Result 2. The proportion of GCs is increasing in the number of females in the bargaining group.

How often do mixed-gender coalitions emerge in FFM and MMF? Note that perfect randomization over partner choice implies that female-male coalitions arise with $2 / 3$ probability in FFM and MMF. Pooling over all games, we find that, $67 \%$ of the time MWCs are mixed gender in FFM-which is consistent with equiprobable partner choice-but only 58\% in MMF (see bottom of Table 4). Probit regression analysis in Table 6 with treatment dummies reveals that this difference is not significant statistically $(\mathrm{p}=0.166)$. Notably, however, in the first half of the experiment mixed coalitions represent 77\% and 57\% of MWCs in FFM and MMF, respectively, and this 20 percentage point difference is significant ( $p=0.047)$. Note that it is the large portion of mixed-gender MWCs in FFM driving this result, as the proportion of such allocations remains similar in the second half for MMF.

Overall, we cannot fully support Hypothesis $3 .^{14}$

Table 6: Marginal Effects of Probit Models for Mixed-gender MWCs

\begin{tabular}{lcccc}
\hline & $(1)$ & $(2)$ & $(3)$ & $(4)$ \\
& All Periods & Periods 1-6 & Period 7-12 & All Periods \\
\hline MMF & -0.087 & $-0.198^{* *}$ & -0.010 & -0.093 \\
& $(0.063)$ & $(0.100)$ & $(0.060)$ & $(0.065)$ \\
Period & & & & $-0.014^{*}$ \\
& & & & $(0.007)$ \\
\hline$N$ & 437 & 193 & 244 & 437 \\
\hline
\end{tabular}

Standard errors clustered at the matching group level.

$* \mathrm{p}<0.1, * * \mathrm{p}<0.05, * * * \mathrm{p}<0.01$

Result 3. Mixed gender coalitions are more common in female majority groups than in male

\footnotetext{
${ }^{13}$ For robustness, we conducted the same regression, but instead of considering the number of women as a continuous variable, we had individual treatment dummies and we also conducted a regression with a dichotomous variable for female majority versus male majority. The direction of our results are largely confirmed, although not all treatment differences reach significance at conventional levels. See the Online Appendix.

${ }^{14}$ In Subsection 4.2, we conduct an exploratory analysis into the possible causes of lower mixed-gender coalitions in MMF. Specifically, we look at first proposals by men and women and behavior of subjects that are left out from a MWC by gender.
} 
majority groups in the first half of the experiment, but there is no difference in the second half.

Turning to our next hypothesis, we now investigate whether there are gender differences in the split of the surplus within mixed coalitions. First, we note that approximately $73 \%$ of all agreement in mixed MWCs are equal split. Women take 49\% of the pie in FFM and 50.4\% in MMF. Regression analysis presented in Table 7 clearly shows that being in the majority or in the minority does not affect women's shares within a MWC. If anything, what we find is a slight gender minority advantage. Computing the mean share difference between minority and majority members (pooling FFM and MMF) we obtain 0.18 , but it is not significantly different from $0(\mathrm{p}=0.324)^{15}$.

Table 7: Linear Regression for Female Share in Mixed-Gender Coalitions

\begin{tabular}{lcccc}
\hline & $(1)$ & $(2)$ & $(3)$ & $(4)$ \\
& All Periods & Periods 1-6 & Period 7-12 & All Periods \\
\hline Male Majority (MMF) & 0.177 & -0.001 & 0.333 & -0.098 \\
& $(0.169)$ & $(0.191)$ & $(0.208)$ & $(0.262)$ \\
Period & & & -0.010 \\
& & & & $(0.025)$ \\
MMF × Period & & & & 0.041 \\
& & & & $(0.036)$ \\
\hline$N$ & & & 144 & 271 \\
$R^{2}$ & 271 & 127 & 0.02 & 0.01 \\
\hline
\end{tabular}

Standard errors clustered at the matching group level.

$* \mathrm{p}<0.1, * * \mathrm{p}<0.05, * * * \mathrm{p}<0.01$

In a nutshell, we reject Hypothesis 4

Result 4. Men and women in mixed-gender coalitions receive the same share regardless of the gender composition of the bargaining group.

\subsubsection{Final Agreements: Efficiency}

We now analyze the efficiency of the agreements. To this end, we assess how quickly agreements are reached, which also allow us to determine aggregate payoffs (and thus, money

\footnotetext{
${ }^{15}$ The p-value was obtained from a linear regression of the share difference on a constant, clustering standard errors at the matching group level
} 
lost) per treatment because of the shrinking pie feature of our game. A summary of these results is presented in Table 8 . Final agreements are reached slowest in FFF (7 seconds) and fastest in MMM (5.32 seconds), the difference being significant at the $10 \%$ level when pooling for all periods and in periods $1-6$, but not in periods $7-12 .^{16}$ Importantly, there is no monotonic relationship with gender composition. The efficiency loss in monetary terms is 30 percent higher in FFF (1.68 EUR) compared to MMM (1.28 EUR). In other words, we reject Hypothesis 5.

Table 8: Efficiency, Delay, and Average Earnings in the Bargaining Games (in Euros)

\begin{tabular}{lcccc}
\hline & FFF & FFM & FMM & MMM \\
\hline Average Time to Agreement (sec) & 7.00 & 5.80 & 6.68 & 5.32 \\
Money Lost (EUR) & 1.68 & 1.39 & 1.60 & 1.28 \\
\hline Agreement reached in: & & & & \\
$\quad$ First Attempt (\%) & 59.5 & 74.3 & 65.6 & 61.2 \\
Second Attempt (\%) & 19.3 & 11.6 & 10.9 & 19.6 \\
Third and Beyond (\%) & 21.2 & 14.1 & 23.5 & 19.2 \\
\hline
\end{tabular}

Result 5. All-male groups are faster in reaching agreements than all-female groups, leading to enhanced efficiency. Nevertheless, the number of interim agreements prior to a final one is equal in these two treatments.

To understand better bargaining delays in our setting, we also take now into account that a temporal delay can be due to inactivity, slow responses, or multiple provisional agreements being broken prior to the final one. We find virtually no difference between FFF and MMM regarding agreements reached in the first attempt (59.5 percent and 61.2 percent of the first provisional agreements bind, respectively). The same holds regarding agreements reached in the second attempt or third attempt and beyond (see bottom part of Table 8). In other words, bargaining behavior is not tougher in the FFF treatment than in the MMM treatment. This indicates that the explanation for the efficiency premium in MMM over FFF is that males are faster at making opening offers, which reduces the overall time of agreements.

\footnotetext{
${ }^{16}$ See Table 4 of the Online Appendix for the detailed econometric analysis. All p-values reported are obtained from OLS regressions with standard errors clustered at the matching group level.
} 


\subsubsection{Are there gender differences in earnings?}

Although we do not have a hypothesis regarding (possible) gender differences in earnings, we are evidently also interested in assessing whether these exist.

From result 4 in Subsection 4.1.1, we know that there is no gender difference in the received share in mixed-gender coalitions in both the FFM and MMF treatments. However, this is only part of the story. That is, do women take a smaller share than men pooling over all agreements (not only mixed coalitions as above) in mixed gender treatments? In a fair division of the pie, a single player would take $1 / 3$ of the resources (in expectation) regardless of gender and gender composition. Regression analysis indicates that men receive more than $1 / 3$ of the surplus in MMF and FFM but it is not significant at conventional levels. ${ }^{17}$

This overall pattern in received shares obviously affects earnings: these differences in shares translate into men earning approximately $22 \%$ more than women in MMF (11.3 EUR vs $9.3, \mathrm{p}=0.0064$, Mann-Whitney test), whereas the gender gap observed in FFM is only $2 \%$ (10.9 vs $10.7, \mathrm{p}=0.146$, Mann-Whitney test). Altogether, the results thus far indicate that the considerable gender gap in earnings in MMF relative to FFM is driven by the disproportionately higher formation of same-gender MWCs in MMF.

Another noteworthy result in Table 9 relates to the contrast of earnings between the FFF and MMM treatments-Men earn significantly more than women (10.77 vs. 10.64, p $=0.045$, Mann-Whitney test). In light of subsection 4.1.2, this latter finding is obviously driven by the longer time that women take to reach final agreements.

Table 9: Efficiency, Delay, and Average Earnings in the Bargaining Games (in Euros)

\begin{tabular}{lcccc}
\hline & FFF & FFM & FMM & MMM \\
\hline Earnings & 10.64 & 10.74 & 10.67 & 10.77 \\
Women & & 10.66 & 9.32 & \\
Men & & 10.89 & 11.34 & \\
\hline
\end{tabular}

We summarize in our next result:

Result 6. Considering the mixed-gender bargaining games, we find a sizable gender gap in earnings in the male majority treatment, whereas the gap is essentially closed in the female majority treatment. Moreover, contrasting the same-gender bargaining games (i.e., FFF vs. MMM treatments), we find that women earn less than men.

\footnotetext{
${ }^{17}$ Testing for whether a male's share is greater than $1 / 3$, the p-values are 0.22 and 0.14 in FFM and MMF, respectively (see regression in Table 3 of the Online Appendix).
} 


\subsubsection{First-proposers}

We now test to our final hypothesis on opening offers, which we conjectured are mostly done by men. Note that in mixed gender treatments, the majority gender should make the opening offer $2 / 3$ of the time if each gender had equal likelihood of proposing first.

In Table 10, we show that men are indeed more likely than women to make the opening offer. When men are the majority, 79 percent of the time one of them moves first. When men are the minority, they move first 45 percent of the time. Both of these proportions are greater than what would arise if both men and women proposed with equal likelihood (see test in table).

Table 10: Proportion of First offers by Males in Mixed-Gender Treatments

\begin{tabular}{lcc}
\hline & FFM & MMF \\
\hline (1) Observed & 0.45 & 0.79 \\
(2) If Random & 0.33 & 0.67 \\
p-value for test ${ }^{1}(1)=(2)$ & 0.059 & 0.003 \\
\hline 1 $^{\text {Test based on a linear regression with st. err. }}$ \\
clustered at matching group level.
\end{tabular}

Thus, the data supports Hypothesis 6.

Result 7. Men are more likely than women to make the first offer regardless of whether they are in majority or minority.

\subsection{Exploratory analysis-Formation of mixed-gender coalitions in FFM and MMF}

Why are mixed-gender coalitions more prevalent in FFM than in MMF? In this section, we conduct an exploratory analysis to understand better the differences in the formation of mixed-gender coalitions between FFM and MMF. Our motivation to take a closer look at the data is the clear lower earnings of women in MMF that we reported in subsection 4.1.3. Thus, we are primarily interested in uncovering why women tend to be left out of a MWCs in MMF.

For this purpose, we focus on three initial events of the bargaining games: $i$. the first offer; ii. the first provisional agreement; and iii. the first counter-offer during the first rat- 
ification period. ${ }^{18}$ The latter element is fundamental to assess how provisional agreements may break down. We also limit our attention to MWCs, which are more straightforward to analyse ${ }^{19}$ and, very importantly, represent the large majority of agreements in our data. Finally, considering the exploratory nature of this section, we do not conduct statistical tests to accommodate for the valid critique of multiple hypothesis testing.

\subsubsection{Why are women excluded from MWCs more often than men in MMF?}

We consider three main reasons why a woman may be more likely to be excluded in implemented MWCs when matched with two men. The most obvious is that man have a preference to make proposals to other men. Our data rejects this explanation: when a male first-mover proposes a MWC, only 44\% proposals are made to the other man, so any existing bias is in favour of women.

Another possible reason is that women are more likely to propose GCs, which are seen as less attractive by men. Although first clicks by women are $12 \%$ more likely to be GCs across all treatments, we see in Figure 2 that women in MMF are marginally less likely to propose GCs. Interestingly, while men's proposals for GCs is consistent across treatments, women seem to conform to the male behavior when in the minority.

A third possibility is that the difference is caused by men being faster at making the opening offer. Indeed, men click first in $79 \%$ of the MMF games, which is more than the $2 / 3$ suggested by chance. But this is clearly not decisive, as $66 \%$ of first MWC provisional agreements in MMF are mixed-gender.

\subsubsection{First provisional agreements and counter-offers}

Given that initial offers are gender non-discriminatory, how does the bargaining process evolve such that women become excluded? In Table 11, we report whether initial MWCs are implemented, and, if not, the type of agreement that follows. In Table 12, we break down the types of clicks (i.e., offers) immediately following initial MWCs. Regarding the first clicks following an initial mixed-gender provisional MWC in MMF, $45 \%$ of clicks by excluded men are MWC proposals to females, compared to $31 \%$ to the other male. Again, as with the first

\footnotetext{
${ }^{18}$ We focus our analysis in these events of the bargaining process because they are straightforward to observe and quantify, and the number of comparable observations available further in time within a game decreases rapidly (most games end after the first agreement and, as time elapses, the ever-decreasing number of games is divided among an exponentially increasing number of possible histories). Also, in around $80 \%$ of games, it is the first or second provisional agreement that is implemented (see table 8.

${ }^{19}$ For example, in a GC, it is not clear who a proposal has been made to.
} 


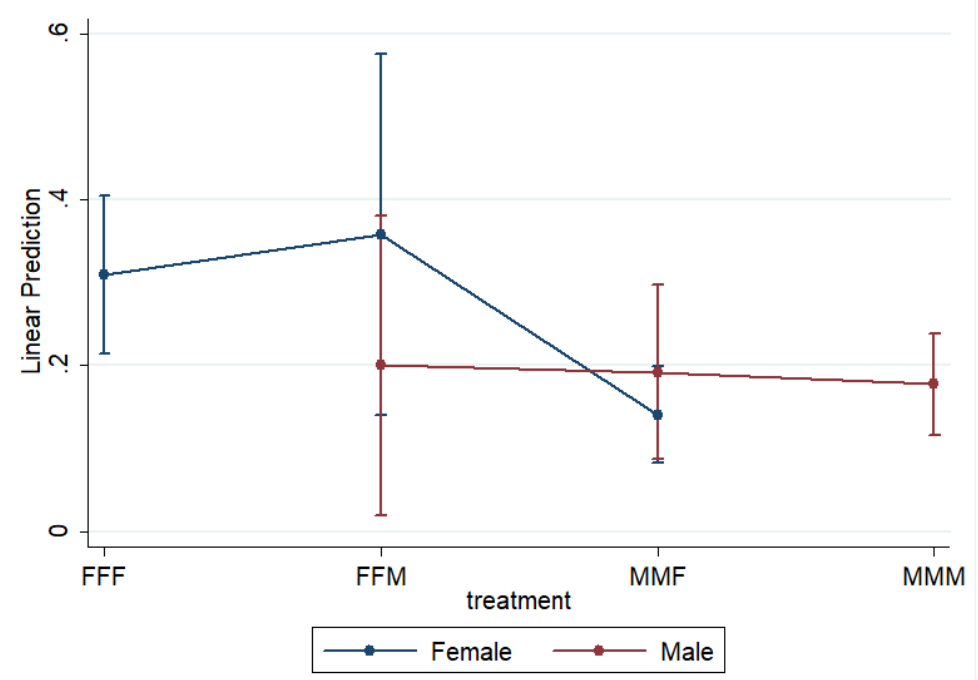

Figure 2: Proportion of first clicks proposing GCs

offers, women are favoured. Thus, we can confidently rule out deliberate discrimination as an explanation for more (than expected if random) women being left out. There is, however, evidence that women are not as good as men at breaking coalitions: excluded women are more likely not to click at all (11\% v 5\%) and more likely to propose GCs (21\% v 14\%), which are less popular, as we have shown in section 4.1.

Furthermore, in MMF, men are more likely to leave a mixed-gender MWC. First of all, $12 \%$ of the first clicks of a coalition member during a provisional agreement are made by the man breaking the agreement compared to $7 \%$ for females. This behavior can also be observed in Table 11: when a new MWC forms with the excluded male, in 27 out of 45 cases it is the man from the initial agreement who leaves.

Result 8. Overall there is no evidence that women are more often (than predicted if random) excluded in MMF because of deliberate discrimination by men, or because women are more prone to propose GCs. Instead, the data suggests that excluded men are more willing to break a mixed-gender coalition, and excluded women are less aggressive in trying to break all-male coalitions.

\section{Discussion and Concluding Remarks}

In general, the results from our experiments demonstrate that the gender composition of a bargaining committee matters in terms of the agreements reached and the bargaining 
Table 11: Fate of first (temporary) MWC agreements

\begin{tabular}{|c|c|c|c|c|c|c|}
\hline \multirow{2}{*}{$\begin{array}{l}\text { Treatment } \\
\text { (First agreement) }\end{array}$} & \multirow{2}{*}{$\begin{array}{l}\text { FFF } \\
(\mathbf{F F})\end{array}$} & \multicolumn{2}{|c|}{ FFM } & \multicolumn{2}{|c|}{ MMF } & \multirow{2}{*}{$\begin{array}{l}\text { MMM } \\
\text { (MMM) }\end{array}$} \\
\hline & & (MF) & (FF) & (MF) & (MM) & \\
\hline $\mathrm{N}$ & 212 & 136 & 64 & 153 & 79 & 250 \\
\hline \multicolumn{7}{|l|}{ Same coalition } \\
\hline Implemented & $122(58 \%)$ & $94(69 \%)$ & $48(75 \%)$ & $92(60 \%)$ & $57(72 \%)$ & $149(60 \%)$ \\
\hline Renegotiation & $11(5 \%)$ & $3(2 \%)$ & $2(3 \%)$ & $12(8 \%)$ & $6(8 \%)$ & $15(6 \%)$ \\
\hline \multicolumn{7}{|l|}{ New coalition } \\
\hline New MF & n.a. & $16(12 \%)$ & $14(22 \%)$ & $18(12 \%)$ & $15(19 \%)$ & n.a. \\
\hline New FF & $64(30 \%)$ & $17(13 \%)$ & n.a. & n.a. & n.a. & n.a. \\
\hline New MM & n.a. & n.a. & n.a. & $27(18 \%)$ & n.a. & $82(33 \%)$ \\
\hline GC & $15(7 \%)$ & $6(4 \%)$ & $0(0 \%)$ & $4(3 \%)$ & $1(1 \%)$ & $4(2 \%)$ \\
\hline
\end{tabular}

Table 12: First click after first (temporary) MWC agreement formed

\begin{tabular}{lcccccc}
\hline $\begin{array}{l}\text { Treatment } \\
\text { (First agreement) }\end{array}$ & FFF & \multicolumn{2}{c}{ FFM } & \multicolumn{2}{c}{ MMF } & MMM \\
\hline $\mathrm{N}$ & 212 & 136 & 64 & 153 & 79 & 250 \\
\hline No click & $15(7 \%)$ & $11(8 \%)$ & $7(11 \%)$ & $8(5 \%)$ & $9(11 \%)$ & $13(5 \%)$ \\
In agreement (M) & n.a. & $11(8 \%)$ & n.a. & $18(12 \%)$ & $14(18 \%)$ & $50(20 \%)$ \\
In agreement (F) & $39(18 \%)$ & $12(9 \%)$ & $10(16 \%)$ & $10(7 \%)$ & n.a. & n.a. \\
Excluded & $158(74 \%)$ & $102(75 \%)$ & $47(73 \%)$ & $117(76 \%)$ & $56(71 \%)$ & $187(75 \%)$ \\
\hline Excluded click & & & & & & \\
Propose GC & $45(28 \%)$ & $31(30 \%)$ & $6(13 \%)$ & $16(14 \%)$ & $12(21 \%)$ & $21(11 \%)$ \\
Other & $14(9 \%)$ & $12(12 \%)$ & $5(11 \%)$ & $12(10 \%)$ & $5(9 \%)$ & $23(12 \%)$ \\
Propose MWC to F & $99(63 \%)$ & $37(36 \%)$ & $36(77 \%)$ & $53(45 \%)$ & n.a. & n.a. \\
Propose MWC to M & n.a. & $22(22 \%)$ & n.a. & $36(31 \%)$ & $39(70 \%)$ & $143(76 \%)$ \\
\hline
\end{tabular}


process that leads to them. We proceed to discuss our findings in light of existing literature on bargaining and the broader field of gender studies in the social sciences.

We find that female representation causally and positively affects the proportion of GC splits, which is evidence that women act more pro-socially than men in a majoritarian bargaining setting. While the decisions made by participants in our experiment, as well as other surplus division experiments (e.g. dictator and ultimatum games), only affect the parties in question, several motivating examples we set forth involve groups making decisions that affect third parties, such as judge panels and boards of directors. Specifically, BourreauDubois et al. (2020) investigate child support decisions by French judges. A three-person panel negotiates how much child support to award under a majority rule and without a predefined structure to the negotiation process. All-women judge panels award the highest level of child support, but there is no monotonic relationship between the number of females in the group and the monetary support and all-male panels provide grant lower support but not significantly. Moreover, using a business management game, Apesteguia et al. (2012) report that groups of three women are more likely to make investments in corporate social responsibility programs that have positive consequences over others. Future experimental work may be useful to understand how exogenous variation in the gender composition of a committee affects outcomes when decisions are being made that have consequences over others that are not part of the negotiation process.

Two decades of laboratory experiments on the popular Baron and Ferejohn (1989) game of structured bargaining, a cornerstone model in political economy, has shown that MWCs are modal but that GCs are non-negligible, representing close to 1/3 of agreements for threeplayer games (Baranski and Morton, 2020). To our knowledge, none of the Baron and Ferejohn (1989) experiments report the proportion of MWCs and GC proposals by gender and none has explicitly controlled for gender balanced recruitment at the session level. Hence, we conjecture that variation in the proportion of MWCs observed in Baron and Ferejohn experiments can be due to variations in gender composition of the sessions' participants. Thus, overlooking this important element in majoritarian bargaining experiments may affect results.

Our experiment uncovers two important gender differences in multilateral bargaining: men are more likely than women to make the opening offer and men fight harder when left out from a coalition. As such, we contribute to the vast experimental economics literature on gender differences which has found that men are more inclined to enter competitions (Niederle and Vesterlund, 2007), contribute ideas (Coffman, 2014), lead a team (Born et al., 
2020), or give advice on how to play strategically (Cooper and Kagel, 2016). Importantly, by now, it is also a robust finding that women's decision-making is influenced by gender stereotypes, as well as by gender composition, when the domain is stereo-typically perceived as disadvantageous for women (Coffman, 2014; Bordalo et al., 2019; Geraldes, 2020).

We do not find evidence supporting our hypothesis that all female groups reach agreements faster. If anything, contrary to our conjecture, time to agreement is longest in FFF and when looking at how many interim coalitions precede the final agreement, no differences emerge between treatments. It is possible that the symmetric nature of our setting is the reason for the lack of variation in bargaining duration especially since equal splits (both in GCs and MWCs) are quite focal. Experimentally altering information about others' payoffs (Roth and Murnighan, 1982), entitlements (Baranski, 2016), or bargaining power (Diermeier and Morton, 2005) may make it harder to reach agreements since these can lead to conflicts over what is an acceptable split and is an area where further experimentation can lead to important insights regarding men's and women's bargaining behavior. 


\section{References}

Agranov, M., Cotton, C., and Tergiman, C. (2020). Persistence of power: Repeated multilateral bargaining with endogenous agenda setting authority. Journal of Public Economics, 184:104126.

Agranov, M. and Tergiman, C. (2014). Communication in multilateral bargaining. Journal of Public Economics, 118:75-85.

Andersen, S., Ertac, S., Gneezy, U., List, J. A., and Maximiano, S. (2018). On the cultural basis of gender differences in negotiation. Experimental Economics, 21(4):757-778.

Apesteguia, J., Azmat, G., and Iriberri, N. (2012). The impact of gender composition on team performance and decision making: Evidence from the field. Management Science, 58(1):78-93.

Azrieli, Y., Chambers, C. P., and Healy, P. J. (2018). Incentives in experiments: A theoretical analysis. Journal of Political Economy, 126(4):1472-1503.

Baranski, A. (2016). Voluntary contributions and collective redistribution. American Economic Journal: Microeconomics, 8(4):149-73.

Baranski, A. and Kagel, J. H. (2015). Communication in legislative bargaining. Journal of the Economic science Association, 1(1):59-71.

Baranski, A. and Morton, R. (2020). The determinants of multilateral bargaining: A comprehensive analysis of baron and ferejohn majoritarian bargaining experiments. NYUAD Social Science Working Paper 37 https://nyuad.nyu.edu/content/dam/nyuad/ academics/divisions/social-science/working-papers/2020/0037(1) .pdf. Last accessed November 1, 2020.

Baron, D. P. and Ferejohn, J. A. (1989). Bargaining in legislatures. American political science review, 83(4):1181-1206.

Bilén, D., Dreber, A., and Johannesson, M. (2020). Are women more generous than men? a meta-analysis. Mimeo. Retrieved from https://papers.ssrn.com/sol3/papers.cfm? abstract_id=3578038.

Bordalo, P., Coffman, K., Gennaioli, N., and Shleifer, A. (2019). Beliefs about gender. American Economic Review, 109(3):739-73. 
Born, A., Ranehill, E., and Sandberg, A. (2020). Gender and willingness to lead: Does the gender composition of teams matter? Review of Economics and Statistics, pages 1-46.

Bourreau-Dubois, C., Doriat-Duban, M., Jeandidier, B., and Ray, J.-C. (2020). Does gender diversity in panels of judges matter? evidence from french child support cases. International Review of Law and Economics, 63:105929.

Boyd, C. L., Epstein, L., and Martin, A. D. (2010). Untangling the causal effects of sex on judging. American journal of political science, 54(2):389-411.

Bradfield, A. J. and Kagel, J. H. (2015). Legislative bargaining with teams. Games and Economic Behavior, 93:117-127.

Castillo, M., Petrie, R., Torero, M., and Vesterlund, L. (2013). Gender differences in bargaining outcomes: A field experiment on discrimination. Journal of Public Economics, 99:35-48.

Coffman, K. B. (2014). Evidence on self-stereotyping and the contribution of ideas. The Quarterly Journal of Economics, 129(4):1625-1660.

Cooper, D. J. and Kagel, J. H. (2016). A failure to communicate: an experimental investigation of the effects of advice on strategic play. European Economic Review, 82:24-45.

Diermeier, D. and Gailmard, S. (2006). Self-interest, inequality, and entitlement in majoritarian decision-making. Quarterly Journal of Political Science, 1(4):327-350.

Diermeier, D. and Morton, R. (2005). Experiments in majoritarian bargaining. In Social choice and strategic decisions, pages 201-226. Springer.

Dittrich, M., Knabe, A., and Leipold, K. (2014). Gender differences in experimental wage negotiations. Economic Inquiry, 52(2):862-873.

Eckel, C., De Oliveira, A. C., and Grossman, P. J. (2008). Gender and negotiation in the small: are women (perceived to be) more cooperative than men? Negotiation Journal, 24(4):429-445.

Eckel, C. C. and Grossman, P. J. (2001). Chivalry and solidarity in ultimatum games. Economic inquiry, 39(2):171-188.

Engel, C. (2011). Dictator games: A meta study. Experimental economics, 14(4):583-610. 
Eriksson, K. H. and Sandberg, A. (2012). Gender differences in initiation of negotiation: Does the gender of the negotiation counterpart matter? Negotiation Journal, 28(4):407428.

Ertac, S. and Gurdal, M. Y. (2012). Deciding to decide: Gender, leadership and risk-taking in groups. Journal of Economic Behavior \& Organization, 83(1):24-30.

Exley, C. L., Niederle, M., and Vesterlund, L. (2020). Knowing when to ask: The cost of leaning in. Journal of Political Economy, 128(3):816-854.

Fehr, E., Naef, M., and Schmidt, K. M. (2006). Inequality aversion, efficiency, and maximin preferences in simple distribution experiments: Comment. American Economic Review, 96(5):1912-1917.

Fischbacher, U. (2007). z-tree: Zurich toolbox for ready-made economic experiments. Experimental economics, 10(2):171-178.

Fréchette, G., Kagel, J. H., and Morelli, M. (2005). Nominal bargaining power, selection protocol, and discounting in legislative bargaining. Journal of Public Economics, 89(8):14971517.

Geraldes, D. (2020). Women dislike competing against men. SSRN Working Paper 3741649 https: //papers.ssrn. com/abstract=3741649. Last accessed December 5, 2020.

Hernandez-Arenaz, I. and Iriberri, N. (2018). Women ask for less (only from men): Evidence from bargaining in the field. Journal of Economic Behavior \& Organization, 152:192-214.

Hernandez-Arenaz, I. and Iriberri, N. (2020). Gender differences in alternating-offer bargaining: An experimental study. CEPR Discussion Paper No. DP12561, Available at SSRN: https://ssrn.com/abstract=3098157. Last accessed December 5, 2020.

Huang, J., Krivkovich, A., Starikova, I., Yee, L., and Zanoschi, D. (2019). Women in the workplace. Retrieved from McKinsey \& Co. website: https://www.mckinsey.com/ featured-insights/gender-equality/women-in-the-workplace-2019. Last accessed December 13, 2020.

Inter-parliamentary Union (2020). 25 years after beijing, ipu analysis shows that gender parity is possible [press release]. https://www.ipu.org/news/press-releases/ 2020-03/25-years-after-beijing-ipu-analysis-shows-gender-parity-possible.

Last accessed December 5, 2020. 
Kagel, J. H., Sung, H., and Winter, E. (2010). Veto power in committees: an experimental study. Experimental Economics, 13(2):167-188.

Lane, T. (2016). Discrimination in the laboratory: A meta-analysis of economics experiments. European Economic Review, 90:375-402.

Laroze, D., Hugh-Jones, D., and Leininger, A. (2020). The impact of group identity on coalition formation. Research \& Politics, 7(4).

Leibbrandt, A. and List, J. A. (2015). Do women avoid salary negotiations? evidence from a large-scale natural field experiment. Management Science, 61(9):2016-2024.

McGee, P. and Constantinides, S. (2013). Repeated play and gender in the ultimatum game. The Journal of Socio-Economics, 42:121-126.

Murnighan, J. K. and Roth, A. E. (1980). Effects of group size and communication availability on coalition bargaining in a veto game. Journal of Personality and Social Psychology, 39(1):92.

Niederle, M. and Vesterlund, L. (2007). Do women shy away from competition? do men compete too much? The quarterly journal of economics, 122(3):1067-1101.

Rand, D. G., Brescoll, V. L., Everett, J. A., Capraro, V., and Barcelo, H. (2016). Social heuristics and social roles: Intuition favors altruism for women but not for men. Journal of Experimental Psychology: General, 145(4):389.

Roth, A. (1987). Bargaining phenomena and bargaining theory. In Roth, A., editor, Laboratory Experimentation in Economics: Six Points of View, pages 14-41. Cambridge University Press Cambridge, UK.

Roth, A. E., Malouf, M. W., and Murnighan, J. K. (1981). Sociological versus strategic factors in bargaining. Journal of Economic Behavior \& Organization, 2(2):153-177.

Roth, A. E. and Murnighan, J. K. (1982). The role of information in bargaining: An experimental study. Econometrica: Journal of the Econometric Society, pages 1123-1142.

Säve-Söderbergh, J. (2019). Gender gaps in salary negotiations: Salary requests and starting salaries in the field. Journal of Economic Behavior \& Organization, 161:35-51. 
Shan, X. (2020). Does minority status drive women out of male-dominated fields? Mimeo. Retrieved from https://sites.google.com/view/xiaoyueshan/research. Last accessed December 15, 2020.

Solnick, S. J. (2001). Gender differences in the ultimatum game. Economic Inquiry, 39(2):189-200.

Sutter, M., Bosman, R., Kocher, M. G., and van Winden, F. (2009). Gender pairing and bargaining-beware the same sex! Experimental Economics, 12(3):318-331.

Tremewan, J. and Vanberg, C. (2016). The dynamics of coalition formation - a multilateral bargaining experiment with free timing of moves. Journal of Economic Behavior Organization, 130:33-46.

Tremewan, J. and Vanberg, C. (2020). Voting rules in multilateral bargaining: using an experiment to relax procedural assumptions. Mimeo. 


\section{A Supporting Tables and Figures}

Table 13: Results from Ultimatum Game Studies with Gender Pairings

\begin{tabular}{lcccccc}
\hline & \multicolumn{3}{c}{ Share Offered (\%) } & \multicolumn{3}{c}{ Rejection Rate (\%) } \\
\cline { 2 - 7 } & EG (2001) & S (2001) & MC (2013) & EG (2001) & S (2001) & MC (2013) \\
\hline \hline Female & 38.5 & 46.8 & 46.6 & 10.5 & 13.5 & 15.9 \\
F to F & 37.8 & 43.1 & 47.2 & 3.1 & 23.1 & 14.7 \\
F to M & 39.8 & 51.3 & 45.9 & 9.4 & 6.3 & 15.6 \\
\hline Male & 36.5 & 46.7 & 45.8 & 14.1 & 4.2 & 16.8 \\
M to M & 36.6 & 47.3 & 45.8 & 18.8 & 4.5 & 18.2 \\
M to F & 36.6 & 44.3 & 45.8 & 17.2 & 0.0 & 17.2 \\
\hline
\end{tabular}

${ }^{1} \mathrm{EG}$ is for Eckel and Grossman (2001). S is for Solnick (2001). MC is for McGee and Constantinides (2013).

Sources: Table 2 in EG (2001) and MC (2013). Data for MC and EG is for all 8 periods. $\mathrm{S}$ is a one-shot game. 
Table 14: Probit models for Grand Coalition Agreement

\begin{tabular}{lcccc}
\hline & All Periods & Periods 1-6 & Period 7-12 & All Periods \\
Number of Females & $0.183^{* * *}$ & $0.180^{* *}$ & $0.219^{* *}$ & 0.142 \\
& $(0.066)$ & $(0.077)$ & $(0.109)$ & $(0.123)$ \\
Period & & & & $-0.130^{* * *}$ \\
& & & & $(0.039)$ \\
Num. Fem. $\times$ Period & & & & 0.010 \\
& & & & $(0.022)$ \\
Constant & $-1.135^{* * *}$ & $-0.838^{* * *}$ & $-1.592^{* * *}$ & $-0.401^{* *}$ \\
& $(0.116)$ & $(0.127)$ & $(0.210)$ & $(0.201)$ \\
\hline$N$ & 1128 & 564 & 564 & 1128 \\
Pseudo-R & 7.76 & 5.41 & 4.01 & 33.71 \\
\hline
\end{tabular}

Standard errors clustered at the group level.

See Table 5 for marginal effects.

$* p<0.1, * * p<0.05, * * * p<0.01$

Table 15: Linear Regression of time to agreement

\begin{tabular}{lccc}
\hline Dep Var. & Time to Agreement & Time to Agreement & Mean Time to Agreement \\
\hline All Male & -1.677 & -1.677 & -1.677 \\
& $(-1.91)$ & $(-1.91)$ & $(-1.82)$ \\
period trend & -0.0972 & & \\
& $(-1.04)$ & & \\
Constant & $7.632^{* * *}$ & $7.000^{* * *}$ & $7^{* * *}$ \\
& $(8.43)$ & $(8.82)$ & $(10.76)$ \\
\hline$N$ & 576 & 576 & 12 \\
$R^{2}$ & 0.013 & 0.011 & 0.249 \\
Clustering & Matching Group & Matching Group & No \\
\hline
\end{tabular}

Standard errors reported in parentheses below coefficient values. $* p<0.05, * * p<0.01, * * * p<$ 0.001 . 


\section{Online Appendix for "An Experiment on Gender}

Representation in Majoritarian Bargaining"

Andrzej Baranski, Diogo Geraldes, Ada Kovaliukaite, and James Tremewan

January 3, 2021

\section{Contents}

1 Description of the Bargaining interface

2 Experimental Instructions and Protocol

3 Supporting Tables and Figures

\section{Description of the Bargaining interface}

The bargaining setting is represented in the form of a two-dimensional simplex consisting of a finite number of circles, each representing a possible division of the twelve points. A possible division includes a specification of three non-negative numbers of points corresponding to each agent in one point increments such that the three numbers sum to twelve. To learn the specific division associated with a given circle, a subject only needs to hover over that circle with the mouse. To propose a particular circle, a subject has to click on that circle, and the proposal is immediately visible to the three subjects in the triad because the outline of the selected circle is colored with the same color associated to the proposing subject. To 


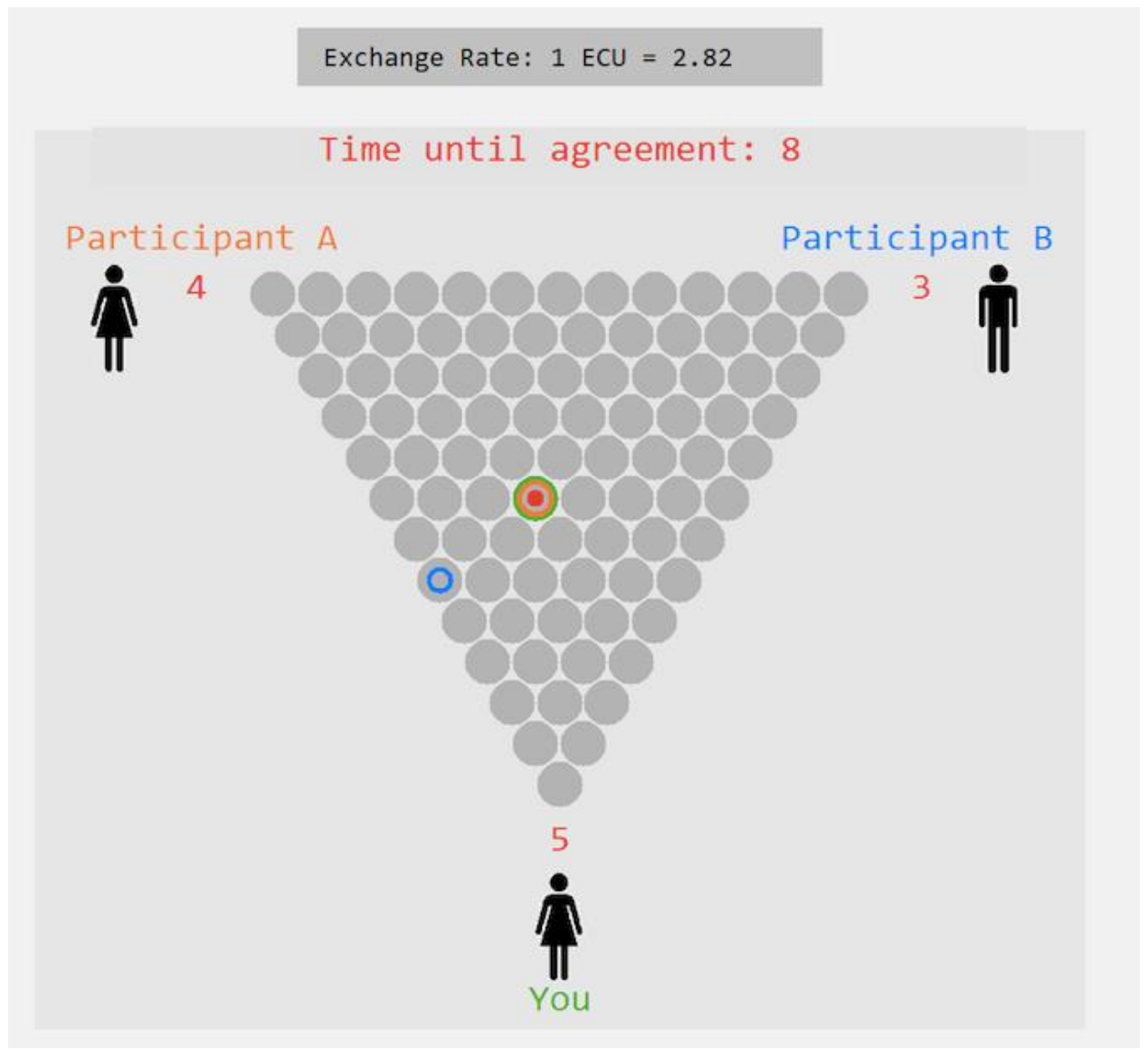

Figure 1: Bargaining Interface

provisionally support an existing proposal, a subject has to click on an outlined circle, and this intention is immediately visible to the three subjects in the triad because the outline of the selected circle gets also "inner-lined" with the color associated with the supporting subject. Importantly, when a provisional agreement starts (i.e., when at least two subjects click on the same circle): i. A red dot instantaneously appears in the center of the circle; ii. The points that each subject gets in case an agreement is reached-which are shown in the vertex of each subject-turn red; iii. A ten-seconds countdown pops up at the top of the simplex to indicate the remaining seconds until actual agreement.

For the sake of clarity, we describe a possible bargaining dynamic taking Figure 1 as a reference. In the experiment, each subject saw the simplex from the perspective of the "You" vertex, which was always located at the bottom vertex of the simplex and associated 
with the green color. The simplex top-left vertex and top-right vertex subjects were always associated with the orange and blue colors, respectively. Thus, Figure 1 indicates that more than two seconds ago, the green subject proposed the division: [5 (points for green subject), 4 (points for orange subject), 3 (points for blue subject)] and exactly two seconds ago the orange subject provisionally accepted the proposal. Subsequently, there are two possible scenarios. If the green and orange subjects do not click anywhere else in the subsequent eight seconds, an agreement is reached regardless of the clicking behavior of the blue subject. In other words, the bargaining process ends. However, if before the subsequent eight seconds elapse, the green subject or the orange subject (or both) click outside the simplex, or click on an alternative division of the twelve points, the provisional agreement on the division $[5,4,3]$ is broken, and the bargaining process continues. Finally, in Figure 1, we also see the (continuously decreasing) exchange rate of points to Euros, which we permanently displayed at the top of the screen during the bargaining process. ${ }^{1}$

\footnotetext{
${ }^{1}$ Evidently, the Euro value of the points when an agreement is reached is determined by the exchange rate at the end of the ratification period. This means that the de facto Euro value of the points for provisionally accepted agreements that start within the last nine seconds of the 150 seconds bargaining time limit is zero. The latter possible bargaining scenario never happened in our experiment.
} 


\section{Experimental Instructions and Protocol}

On the next pages, we reproduce the experimental instructions. 


\section{MAIN PART OF THE EXPERIMENT}

\section{ON-SCREEN INSTRUCTIONS:}

In this part of the experiment, participants will interact in groups of three. The interaction will be repeated twelve times. In what follows, we will call each repetition of the interaction a "round".

During each round, the three members of a group will have the opportunity to distribute $\mathbf{1 2}$ POINTS amongst themselves.

The points you receive will determine how much money you earn at the end of the experiment (exactly how will be explained later, but the more points you receive, the more money you can expect to earn).

In order to help you understand exactly how the interactions work, we will now demonstrate the functioning of the program on your screen.

There will be a short tutorial. In the tutorial, you will be shown the screen that will be used during the real rounds. How to understand this screen and use it to interact with the other participants in your group is explained to you in the printed instructions you have been given.

During this tutorial no money will be awarded. The purpose of this tutorial is only to help you understand how the program works. You will be informed before the real interactions begin. Please follow the printed instructions carefully. It is important to understand how the program works!

PLEASE CLICK "Begin Tutorial" IF YOU ARE READY TO BEGIN THE TUTORIAL. Follow the printed instructions to complete the tutorial. 


\section{TUTORIAL STAGE 1}

Read the instructions below and complete ALL the listed exercises.

Note: you will not be able to finish the tutorial if you do not complete ALL the listed exercises.

DO NOT click "Move to stage 2" until you are specifically asked to do so.

\section{UNDERSTANDING THE TRIANGLE}

- The participants in your group must decide how to divide 12 points amongst yourselves.

- On your screen, you will see small circles arranged in the form of a large triangle. Each circle represents a different way of allocating the points amongst you and the other two participants you are interacting with in a given round.

- The corners of the triangle are labeled "You", "Participant A", and "Participant B".

- The circles in the corners of the triangle correspond to allocations in which the indicated corner participant receives all available points, while the others receive no points.

- The closer a circle is to a given corner, the more points the corresponding allocation assigns to that participant.

- If you move your mouse over a circle, the corresponding points to be allocated to each participant are displayed in the appropriate corners of the triangle.

- EXERCISES:

- Move your mouse around the triangle until you understand how the circles are arranged.

- Click on a circle to select it. Notice that the selected circle is marked in green.

○ Click outside the triangle. The green circle should disappear. During the real interactions, when you click on a circle, this will be shown on the screens of the two other participants you are interacting with, and it will disappear from their screens if you click outside the triangle. If two or more participants select the same circle continuously for 10 seconds, the points are allocated accordingly in that round.

\section{MAKING AGREEMENTS}

- During the real interactions, any of the three participants (including you) may click on any circle at any time.

- When you click on a circle, the other two participants in your group will see this circle marked on their screen. 
- When another participant in your group clicks on a circle on their screen, it will be marked on your screen in the color corresponding to that participant: orange for "Participant A", blue for "Participant B".

- Clicking on an unmarked circle is like suggesting that division.

- Clicking on a circle marked by another participant is like provisionally accepting the division they have suggested. The offer will only be really accepted and determine the number of points earned in that round if neither you nor the other participant clicks elsewhere in the following 10 seconds.

- When another participant clicks on a circle you have marked, they have provisionally accepted the division you have suggested. Again, your offer will only be really accepted and determine the number of points earned in that round if neither you nor the other participant clicks elsewhere in the following 10 seconds.

- When there is a provisional agreement in place, a red circle will appear in the appropriate circle.

- When there is a provisional agreement in place, a clock will start counting down "Time until agreement" from 10 seconds to let you know when it will be really accepted if neither participant clicks elsewhere. You can see this shown in red on the picture at the end of these instructions.

- For the division to be implemented at least two of the three group members must arrive at an agreement.

\section{THE VALUE OF POINTS, TIME LITMITS and ROUND EARNINGS}

- At the start of each round, each point will be worth $€ 3$. Thus, at the start of each round, you have $€ 3 \times 12$ points $=€ 36$ to divide within your group.

- The value of the points will decrease throughout the round. In particular, a point will be worth $€ 0.02$ ( 2 cents) less in each second. For example, after 20 seconds pass since the beginning of a round, each point will be worth $€ 3-20$ seconds $\times € 0.02=€ 2.6$.

- The exchange rate of points to euros at a given point in time will be shown at the top left side of the screen. You can see this in the picture at the end of these instructions.

- The round will end, when an agreement is reached (that is, when at least two participants continuously agree on the allocation of points for 10 seconds) or when the exchange rate reaches €0 per point. If there is no agreement after the exchange rate has reached €0 per point, the round will end, and no one will receive any points.

- If the agreement is finalized, your earnings for a particular round will be determined by the number of points allocated to you in that round and the exchange rate at the time when the agreement is confirmed: 
Your earnings for a round

$=$ number of points allocated to you in the circle under agreement

$\times$ exchange rate at the time when the agreement is confirmed

\section{DO NOT CLICK “Move to stage 2" JUST YET!}

- When you click "Move to stage 2" two things will happen:

- Two circles, one blue and one orange, will appear on random circles in the triangle. These are what it looks like when the participants you are interacting with click on their triangle, but the locations of these circles have been chosen by the computer at random. You will not be interacting with real participants for now.

- The clock will start and the exchange rate of points to euros will start to decrease. Don't worry! The points received in this tutorial will not affect how much money you earn in this experiment. Also, you can repeat this part of the tutorial as many times as you like.

- There will be only two differences between Stage 2 of the tutorial and the real interactions:

- In the tutorial rounds the points you receive will not affect how much money you earn.

- In the real interactions the blue and orange circles may move as the participants you are interacting with click on different circles on their triangles.

\section{TUTORIAL STAGE 2}

\section{CLICK ON "Move to stage 2" and complete the following exercises.}

\section{- Exercises:}

- Watch the top line of the screen and see how the exchange rate of points to euros decreases.

- Click the blue circle and see how the "Time until agreement" starts counting down until zero, when the round will "end" and the number of points you receive is determined. Then click "Play another tutorial round" and repeat with the orange circle and click "Play another tutorial round" again.

- Now try clicking on the blue circle then clicking on an empty circle or outside the triangle before the 10 seconds are up. See how the "Time until agreement" starts counting down and then disappears when you click elsewhere.

- Now try clicking on the blue circle then clicking on the orange circle before the 10 seconds are up. See how the "Time until agreement" starts counting down and then starts again at 10 seconds when you click on the second circle.

○ You can now experiment with the tutorial screen as much as you like. 
When you have understood how the interactions work, click on "Finish tutorial" button. When all participants have finished the tutorial, the real interactions will begin. 
Exchange Rate: $1 \mathrm{ECU}=2.82$

Time until agreement: 8

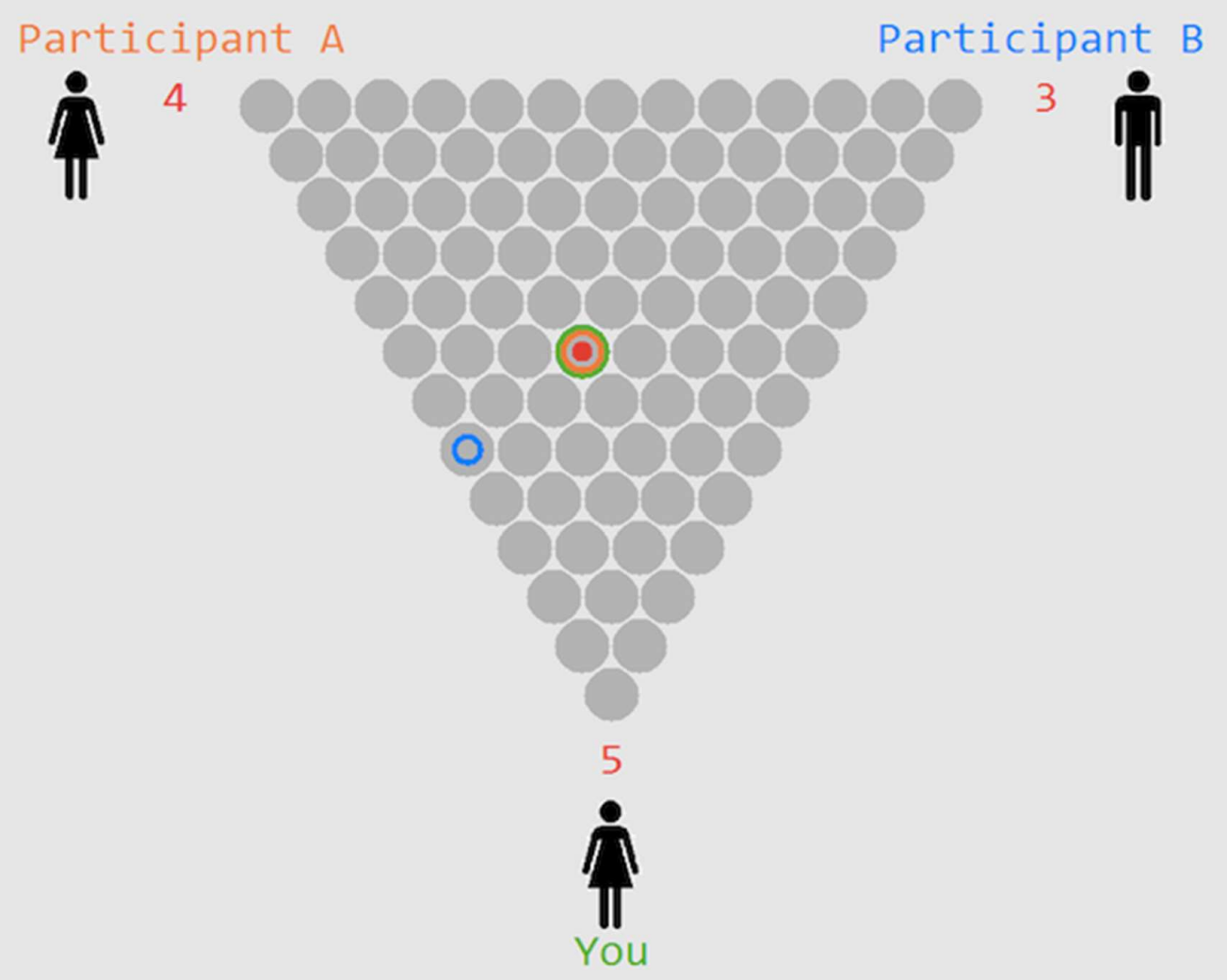




\section{ON-SCREEN INSTRUCTIONS:}

You have finished the tutorial.

You will now interact 12 times with real participants.

The participants with whom you will interact will be randomly determined at the beginning of each round.

The other participants in your group will always be referred to on your screen as "Participant A" and "Participant B".

At the end of the experiment, one of these rounds will be randomly selected and you will be paid according to your earnings in that round, and that round only.

You may now ask questions about the instructions on this page and way the program works.

If you have a question, please raise your hand and ask it quietly when an experimenter comes.

If you have no questions, please click "Continue" and wait for the real rounds to begin. 


\section{Supporting Tables and Figures}

Table 1: Probability of Grand Coalition Agreement Marginal Effects

\begin{tabular}{lcc}
\hline & $\begin{array}{c}\text { Model with } \\
\text { Trt. Dummies }\end{array}$ & $\begin{array}{c}\text { Model with } \\
\text { Gender Majority }\end{array}$ \\
\hline MMF & 0.024 & \\
& $(0.052)$ & \\
FFM & $0.129^{*}$ & $(0.074)$ \\
& $0.132^{* *}$ & \\
FFF & $(0.057)$ & \\
& $-0.030^{* * *}$ & $-0.029^{* * *}$ \\
Period & $(0.005)$ & $(0.005)$ \\
& & $0.119^{* *}$ \\
Females are Majority ${ }^{*}$ & & $(0.051)$ \\
& 1128 & 1128 \\
\hline$N$ & &
\end{tabular}


Table 2: Gender Mixed Coalitions and Payoffs in MWCs

\begin{tabular}{lcc}
\hline & $\begin{array}{c}\text { Female Majority } \\
(\mathrm{FFM})\end{array}$ & $\begin{array}{c}\text { Male Majority } \\
(\mathrm{MMF})\end{array}$ \\
\hline $\begin{array}{l}\text { Proportions: } \\
\text { Mixed Coalitions }\end{array}$ & 0.67 & 0.58 \\
Majority Advantage & 0.13 & 0.10 \\
Equal Split & 0.72 & 0.76 \\
$\quad$ Minority Advantage & 0.15 & 0.14 \\
\hline Proportion of total fund: & & \\
Gender Majority Share & 0.49 & 0.5 \\
$\quad$ Gender Minority Share & 0.51 & 0.5 \\
\hline
\end{tabular}

This table shows some evidence for positive gender minority discrimination.

Table 3: Tobit for Share of the Surplus in Mixed Gender Treatments

\begin{tabular}{lcc}
\hline Male & 0.010 & $(0.033)$ \\
Male Majority (MMF) & $-0.061^{* *}$ & $(0.031)$ \\
Male $\times$ MMF & 0.077 & $(0.053)$ \\
_cons & $0.291^{* * *}$ & $(0.014)$ \\
\hline$N$ & 1656 & \\
F-statistic & 1.83 & \\
\hline
\end{tabular}

Standard errors clustered at the study level in parentheses. ${ }^{*} \mathrm{p}<0.1,{ }^{* *} \mathrm{p}<0.05,{ }^{* * *} \mathrm{p}<0.01$

A Wald test for Male $+\mathrm{MMF}+$ Male $\times \mathrm{MMF}+$ Cons $=1 / 3$ yields a p-value of 0.22 . Thus, we reject that a male subject receives on average more than $1 / 3$ of the surplus in MMF.

A Wald test for Male + Cons $=1 / 3$ yields a $p$ value of 0.14 . Thus, we reject that a male subject receives on average more than $1 / 3$ of the surplus. 
Table 4: Linear Regression for Time to Final Agreement

\begin{tabular}{lcccc}
\hline & $(1)$ & $(2)$ & $(3)$ & $(4)$ \\
& All Periods & Periods 1-6 & Period 7-12 & All Periods \\
\hline Constant & $7.000^{* * *}$ & $7.354^{* * *}$ & $6.646^{* * *}$ & $8.049^{* * *}$ \\
& $(0.777)$ & $(0.783)$ & $(0.865)$ & $(0.930)$ \\
FFM & -1.203 & -1.224 & -1.182 & -0.454 \\
MMF & $(1.385)$ & $(1.337)$ & $(1.564)$ & $(1.737)$ \\
& -0.322 & -0.485 & -0.160 & -0.705 \\
MMM & $(1.036)$ & $(1.124)$ & $(1.149)$ & $(1.369)$ \\
Period & $-1.677^{*}$ & $-1.965^{*}$ & -1.389 & $-2.511^{*}$ \\
FFM $\times$ Period & $(0.859)$ & $(0.972)$ & $(1.072)$ & $(1.323)$ \\
& & & & -0.161 \\
MMF $\times$ Period & & & & $(0.120)$ \\
MMM $\times$ Period & & & & -0.115 \\
$\mathrm{R}^{2}$ & & & & $0.146)$ \\
\hline
\end{tabular}

Base level is treatment FFF.

Standard errors in parentheses clustered at the matching group level.

${ }^{*} p<0.1,{ }^{* *} p<0.05,{ }^{* * *} p<0.01$ 